\title{
Dyslipidemia in Patients with Type 2 Diabetes Mellitus in a Tertiary Care Centre: A Descriptive Cross-sectional Study
}

\author{
Ram Kumar Mehta, ${ }^{1}$ Puru Koirala, ${ }^{1}$ Ram Lala Mallick, ${ }^{2}$ Surya Parajuli, ${ }^{3}$ Rajneesh Jha ${ }^{1}$ \\ 'DepartmentofInternalMedicine,BiratMedicalCollegeTeaching Hospital,Budhiganga,Morang, Nepal, ${ }^{2}$ Department \\ of Biochemistry, Birat Medical College Teaching Hospital, Budhiganga, Morang, Nepal, ${ }^{3}$ Department of Community \\ Medicine, Birat Medical College Teaching Hospital, Budhiganga, Morang, Nepal.
}

\section{ABSTRACT}

Introduction: Dyslipidemia is highly prevalent among type 2 diabetic patients. It increases the risk of atherosclerosis and consequent mortality in diabetic patients. The aim of this study was to find out the prevalence of dyslipidemia among type 2 diabetic patients.

Methods: This was a descriptive cross-sectional study in 355 type 2 diabetic patients at tertiary care hospital from 15th May, 2020 to 15th November, 2020 after taking ethical clearence from Institutional Review Committee (Reference no. IRC-PA-052/2077-78). Convenience sampling was done. Demographic and lipid profile variables were recorded based on the structured questionnaires. Data were analyzed by Statistical Package for the Social Sciences version 20. Point estimate at 95\% Confidence Interval was calculated along with frequency and percentage for binary data.

Results: Out of total 355 cases of type 2 Diabetes mellitus, prevalence of dyslipidemia was 224 (63.1\%). It was more prevalent in male 145 (69.4\%) than female 79 (54.1\%). Increased Low density Lipoprotein (94.2\%) was the most prevalent type followed by mixed dyslipidemia $(91.1 \%)$.

Conclusions: Dyslipidemia was common among type 2 diabetic patients and was higher in male gender, older age, obesity and longer duration of diabetes. Hence type 2 diabetic patient should undergo the routine monitoring of blood sugar and lipid profile so that any abnormalities can be identified and preventive measures along with interventions can be initiated at the earliest.

Keywords: dyslipidemia; prevalence; T2DM.

\section{INTRODUCTION}

Dyslipidemia is one of the major modifiable risk factor for the development of type 2 diabetes mellitus (T2DM), atherosclerosis, stroke and cardiovascular diseases. ${ }^{1}$ The occurrence of T2DM exists as the third major noncommunicable disease in Nepal. ${ }^{2}$

In Nepal, prevalence of dyslipidemia is $63.8 \%$ in eastern, $61.0 \%$ in central and $90.7 \%$ in mid-western region. ${ }^{3}$ Dyslipidemia is one of the important risk factor for vascular complications in diabetic patients. It increases free fatty acid flux secondary to insulin resistance and aggravated by increased inflammatory adipokine. ${ }^{4}$ T2DM increases the risk of cardiovascular disease (CVD) several fold. ${ }^{5}$

Early detection and proper management of dyslipidemia in diabetic patient helps in prevention of diabetes related complications. ${ }^{6}$ Thus, this study aimed to determine the prevalence of dyslipidemia among Nepalese type 2 diabetic population residing in this region.

\section{METHODS}

This is a descriptive cross-sectional study conducted at Birat Medical College Teaching Hospital, Nepal from 15th May 2020 to 15th November 2020. A total of 355 patients with Type 2 Diabetes Mellitus (Age >30 years) who attended medicine Out Patient Department were enrolled based on convenience sampling technique.

Correspondence: Dr. Ram Kumar Mehta, Department of Internal Medicine, Birat Medical College Teaching Hospital, Budhiganga, Morang, Nepal, Email: mehtark0123@gmail.com, Phone: +977-9841863799. 
Prior to the study, ethical clearance was taken from Instutional Review committee (IRC-PA-052/2077-78). Written consent was taken from all type 2 diabetic patients of age more than 30 years and willing to be enrolled in the study. Patient presenting in diabetic ketoacidosis, hyperglycemic hyperosmolar state and denied to give written consent were excluded from the study. Sample size was calculated using the formula,

$\mathrm{n}=\mathrm{Z}^{2} \times \mathrm{p} \times \mathrm{q} / \mathrm{e}^{2}$

$=(1.96)^{2} \times 0.638 \times 0.362 / 0.05^{2}$

$\begin{aligned} &=(1.96) \\ &=355 \\ & \text { where, }\end{aligned}$

$\mathrm{n}=$ required sample size

$Z=1.96$ at $95 \%$ Confidence Interval $(\mathrm{Cl}$

$\mathrm{p}=$ prevalence of the dyslipidemia, $63.8 \%^{3}$

$q=1-p$

$\mathrm{e}=$ margin of error, $5 \%$

Sample size of 355 was considered in this study. All patients who met inclusion criteria were sent for lipid profile assay in department of biochemistry. Sample was collected in overnight fasting state. All participants were asked relevant questions to note demographic information co-morbid conditions based on pre infrumation, co-morbided questionnaires.

For serum lipids, National Cholesterol Education Programme Adult Treatment Panel III (NCEPATPIII) guideline was referred. According to NCEPATPIII guideline hypercholesterolemia-serum total cholesterol level $\geq 200 \mathrm{mg} / \mathrm{dl}$; hypertriglyceridemiaserum TG level $\geq 150 \mathrm{mg} / \mathrm{dl}$; low HDL-C level $\leq 40 \mathrm{mg} /$ dl for men and $\leq 50 \mathrm{mg} / \mathrm{dl}$ for women; high LDL-C level $\geq 100 \mathrm{mg} / \mathrm{dl}$. Dyslipidemia is defined by presence of one or more than one abnormal serum lipid concentration. Mixed dyslipidemia is defined by presence two or more than two abnormal value of above mentioned lipid parameters. T2DM was designated to the patients who were already diagnosed by a physician and under treatment and/or who had plasma glucose levels above the cut off values recommended by American Diabetes Association (ADA) criteria.

Data were entered and analyzed using the Statistical Package for the Social Sciences version 20.0 (SPSS 20) for Windows. Demographic variables were analyzed using descriptive statistics. Data were collected throughout the study period to meet the sample size for the study.

\section{RESULTS}

The prevalence of dyslipidemia among type 2 diabetics is $224(63.1 \%)$. Similarly, prevalence of dyslipidemia among male is $145(69.4 \%)$ and female is $79(54.1 \%)$. Out of 355 patients, $209(58.9 \%)$ were male and 146
(41.1\%) were female. Mean age of participants was $53.10 \pm 13.74$ years (Table 1 )

\begin{tabular}{|c|c|c|c|}
\hline $\begin{array}{l}\text { Table 1. Soc } \\
(\mathrm{n}=355) \text {. }\end{array}$ & emogra & details & ants \\
\hline Variables & Male & Female & Total \\
\hline n (\%) & $209(58.9)$ & $146(41.1)$ & $355(100)$ \\
\hline $\begin{array}{l}\text { Mean age } \\
\text { (years) }\end{array}$ & $53.99 \pm 13.86$ & $51.82 \pm 13.50$ & $53.10 \pm 13.74$ \\
\hline \multicolumn{4}{|l|}{\begin{tabular}{|l}
$\begin{array}{l}\text { Age group } \\
\text { (years) }\end{array}$ \\
\end{tabular}} \\
\hline $30-44$ & $61(29.2 \%)$ & $49(33.6 \%)$ & $110(31 \%)$ \\
\hline $45-60$ & $74(35.4 \%)$ & $47(32.2 \%)$ & 121 (34.1\%) \\
\hline 60-74 & $62(29.7 \%)$ & $44(30.1 \%)$ & 106 (29.9\%) \\
\hline$>75$ & $12(5.7 \%)$ & $6(4.1 \%)$ & $18(5.1 \%)$ \\
\hline \multicolumn{4}{|l|}{ BMI $\left(\mathrm{kg} / \mathrm{m}^{2}\right)$} \\
\hline$<25$ & $95(45.5 \%)$ & 75 (51.4\%) & 170 (47.9\%) \\
\hline$>25$ & $114(54.5 \%)$ & $71(48.6 \%)$ & 185 (52.9\%) \\
\hline $\begin{array}{l}\text { Mean Waist } \\
\text { Circumference } \\
(\mathrm{cm})\end{array}$ & 90.74 & 88.34 & 89.75 \\
\hline \multicolumn{4}{|l|}{ Diet } \\
\hline Vegetarian & $15(7.2 \%)$ & $38(26 \%)$ & $53(14.9 \%)$ \\
\hline $\begin{array}{l}\text { Non } \\
\text { vegetarian }\end{array}$ & 194 (92.8\%) & $108(74 \%)$ & $302(85.1 \%)$ \\
\hline \multicolumn{4}{|l|}{ Smoking } \\
\hline $\begin{array}{l}\text { Current } \\
\text { smoker }\end{array}$ & $58(27.8 \%)$ & $30(20.5 \%)$ & $88(24.8 \%)$ \\
\hline Ex-smoker & $54(25.8 \%)$ & $18(12.3 \%)$ & $72(20.3 \%)$ \\
\hline Non-smoker & $97(46.4 \%)$ & $98(67.1 \%)$ & 195 (54.9\%) \\
\hline
\end{tabular}
Ml; body mass index

Most common type of dyslipidemia among type diabetics was high LDL was 211 (94.2\%) followed by mixed dyslipidemia 204 (91.1\%) (Table 2).

\begin{tabular}{|lc|}
\hline $\begin{array}{l}\text { Table 2. Prevalence of abnormal } \\
\text { T2DM patients }(\mathrm{n}=224) \text {. }\end{array}$ & \\
\hline & $\mathrm{n}(\%)$ \\
\hline Dyslipidemia & $224(63.1)$ \\
Male & $145(69.4)$ \\
Female & $79(54.1)$ \\
High total cholesterol & $184(82.1)$ \\
Low HDL & $105(46.9)$ \\
Isolated low HDL & $8(3.6)$ \\
High LDL & $211(94.2)$ \\
Isolated high LDL & $7(3.1)$ \\
High triglyceride & $165(73.7)$ \\
Isolated high triglyceride & $5(2.2)$ \\
Mixed dyslipidemia & $204(91.1)$ \\
\hline
\end{tabular}

\begin{tabular}{|c|c|c|c|c|c|c|}
\hline & & High TC & Low HDL & High LDL & High TG & Mixed \\
\hline & & $n(\%)$ & $n(\%)$ & $n(\%)$ & $n(\%)$ & $n(\%)$ \\
\hline \multicolumn{7}{|l|}{ Gender } \\
\hline Male & 209 & $116(55.5)$ & $50(23.9)$ & $136(65.1)$ & $108(51.7)$ & $130(62.2)$ \\
\hline Female & 146 & $68(46.6)$ & $55(37.7)$ & $75(51.4)$ & $57(39)$ & $74(50.7)$ \\
\hline \multicolumn{7}{|l|}{ Age group } \\
\hline $30-44$ & 110 & $13(11.8)$ & $13(11.8)$ & $20(18.2)$ & $17(15.5)$ & $17(15.5)$ \\
\hline $45-59$ & 121 & $60(49.6)$ & $18(14.9)$ & $69(57.0)$ & $49(40.5)$ & $66(54.5)$ \\
\hline $60-74$ & 106 & $94(88.7)$ & $59(55.7)$ & $104(98.1)$ & $82(77.4)$ & $103(97.2)$ \\
\hline$>75$ & 18 & $17(94.4)$ & $15(83.3)$ & $18(100)$ & $17(94.4)$ & $18(100)$ \\
\hline \multicolumn{7}{|l|}{ BMI } \\
\hline$<25$ & 170 & $34(20)$ & $20(11.8)$ & $38(22.4)$ & $33(19.4)$ & $38(22.4)$ \\
\hline$>25$ & 185 & $150(81.1)$ & $85(45.9)$ & $173(93.5)$ & $132(71.4)$ & $166(89.7)$ \\
\hline \multicolumn{7}{|c|}{ Duration of Diabetes (years) } \\
\hline$<5$ & 149 & $29(19.5)$ & $25(16.8)$ & $37(24.8)$ & $30(20.1)$ & $34(22.8)$ \\
\hline $5-10$ & 65 & $39(60.0)$ & $9(13.8)$ & $44(67.7)$ & $28(43.1)$ & $43(66.2)$ \\
\hline $\mid 10-15$ & 51 & $32(62.7)$ & $20(39.2)$ & $41(80.4)$ & $32(62.7)$ & $38(74.5)$ \\
\hline$>15$ & 90 & $84(93.3)$ & $51(56.7)$ & $89(98.9)$ & $75(83.3)$ & $89(98.9)$ \\
\hline \multicolumn{7}{|l|}{ Diet } \\
\hline Vegetarian & 53 & $30(56.6)$ & $18(34.0)$ & $32(60.4)$ & $24(45.3)$ & $31(58.5)$ \\
\hline Non vegetarian & 302 & $154(51.0)$ & $87(28.8)$ & $179(59.3)$ & $141(46.7)$ & $173(57.3)$ \\
\hline
\end{tabular}

Prevalence of dyslipidemia was high in patients with high BMI and high LDL was the most prevalent one 173 (93.5\%). Prevalence of single and mixed dyslipidemia was higher in patients with longer duration of diabetes (Table 3).

DISCUSSION

The aim of our study was to determine the prevalence of dyslipidemia among type 2 diabetic patients residing in Eastern Nepal. Majority of patients were male, male to female ratio was 1.4:1. Most of the participants were non-vegetarian (85.1\%). Similarly more than half of patients were having higher BMI $(52.9 \%)$ which is similar to study conducted in Thailand. ${ }^{9}$ Changes in lifestyle such as consumption of western style diets which include high calorie foods with increased carbohydrate, fat, and red meat consumption and low fiber diet have contributed to the increased prevalence of obesity, metabolic syndrome and T2DM. ${ }^{10}$

There was high prevalence of dyslipidemia in patients with diabetes $(63.1 \%)$ which is similar to study done by Das et al." However this was slight lower than other study reported from other part of the country.12 Our study demonstrated higher prevalence of dyslipidemia respectively which is comparable to similar study done at tertiary center in this region." When focusing on the subtypes of dyslipidemia, most prevalent was high LDL (94.2\%) followed by mixed dyslipidemia $(91.1 \%)$, (73.7\%) and low (73.7\%) and low HDL (46.9\%). High LDL was most prevalent dyslipidemia in both male and female which was $65.1 \%$ and $51.4 \%$ respectively. These findings are similar to that of reports from Nepal and elsewhere. Atherogenic dyslipidemia was present in most of the patients which might be due to insulin resistance and is exaggerated by the hyperglycemic state and risk for atherosclerotic cardiovascular disease.

Dyslipidemia was more prevalent in patients having higher BMI and high LDL was the most prevalent (93.5\%) followed by mixed dyslipidemia (89.7\%). This is in accordance to the report from different regions is Nepal. ${ }^{3}$ Higher BMI is directly associated with factominal obesity which is one of the important risk adipose tissue can lead to insulin resistance as well as dyslipidemia. 15,16 Prevalence of dyslipidemia was shown to be increasing with ageing in our study which is similar to study done by Pokharel, et al. As age increases there will be reduced expression of hepatic LDL-C receptors leading to increased tota cholesterol and IDL level due to impaired clearance and most common abnormality was high 
from plasma. ${ }^{17}$ Prevalence of dyslipidemia was shown to be more in patient with longer duration of diabetes and most common lipid abnormality was high LDL. This is supported by other study as well.18 The exact mechanism by which altered lipid profile is more deranged with disease duration is not very well understood.

This is a small cross-sectional hospital based study representing diabetic patients from the eastern part of Nepal. It did not analyze the effect of lipid lowering has not ben assessed in this study. The fing has not been assessed in this study. The findings of this study, therefore, should be interpreted within context, and may in diabetic patients.

CONCLUSIONS

Our study showed high prevalence of dyslipidemia among type 2 diabetic patients. Dyslipidemia was higher in male gender, older age, obesity and longer

REFERENCES

1. Qi L, Ding $X$, Tang $\mathrm{W}$, Li Q, Mao D, Wang Y. Prevalence and risk factors associated with dyslipidemia in Chongqing, Chis. The I DOI]

2. Bhandari GP, Angdembe MR, Dhimal M, Neupane $\mathrm{S}$, (a) IDOH

3. Pokharel DR, Khadka D, Sigdel M, Yadav NK, Acharya S, Kafle R, et al. Prevalence and pattern of dyslipidemia in notes. 2017 Dec 1:10(1):146. [Robved I Fell Tex I DOH

4. Chehade JM, Gladysz M, Mooradian AD. Dyslipidemia in type 2 diabetes: prevalence, pathophysiology, and DOII

5. Juutilainen A, Lehto S, Rönnemaa T, Pyörälä K, Laakso M. Type 2 diabetes as a "coronary heart disease equivalent":

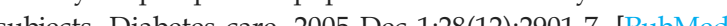
| Full Text | DOI]

6. Lazarte J, Hegele RA. Dyslipidemia management in adults with diabetes. Canadian journal of diabers. 2020 Feb

7. Expert Panel on Detection E. Executive summary of the third report of the National Cholesterol Education Program (NCEP) expert panel on detection, evaluation, and treatment III). Jama. 2001 May 16;285(19):2486. [PubMed | DOI]

8. American Diabetes Association. 2. Classification and diagnosis of diabetes: stundurds. Co melical care in duration of diabetes. These findings should raise awareness regarding prevalence of dyslipidemia among type 2 diabetics to healthcare providers and will help in management of dyslipidemia. Indeed, efforts should be made to increase awareness to public about diabetic dyslipidemia, benefits of change in lifestyle and regular intake of medication and thus decreasing the prevalence of dyslipidemia among diabetic patients.

ACKNOWLEDGEMENTS

We would like to express our gratitude to all the participants for participation in this study. We would like to thank department of Biochemistry for evaluation of lipid parameters. We would like to express our sincere thanks to Mrs. Priyanka Pritam, Dr. Amit Kumar Singh and Dr. Suresh Mehata in data interpretation, analysis and write up.

Conflict of Interest: None.

diabetes -2019. Diabetes care. 2019 Jan 1;42(Supplement 1):S13-28. [PubMed | Full Text | DOI]

9. Narindrarangkura P, Bosl W, Rangsin R, Hatthachote P. Prevalence of dyslipidemia associated with complication in diabetic patients: a nationwide study in Thailand. Lipids Health and Disease. 2019 Dec 1;18(1):90. [PubMed | Full ext! DOI]

10. Misra A, Singhal N, Khurana L. Obesity, the metabolic syndrome, and type 2 diabetes in developing countries: role of dietary fats and oils. Journal of the American College of

1. Das BK, Prassan N, Ansari MF, Agrawal K, Tripathi S, Niraula A. Dyslipidemic profile in Type 2 Diabetes Mellitus A hospital-based study from Eastern Nepal. Journal of Boil

12. HK S. Prevalence and Pattern of Dyslipidemia among Type 2 Diabetes Mellitus Patients in a Tertiary Center Hosp

13. Borle AL, Chhari N, Gupta G, Bathma V. Study of prevalence and pattern of dyslipidaemia in type 2 diabetes mellitus patients attending rural health training centre of medical Med Public Health. 2016 Jan;3(1):140-4. [Eull Text | DOn]

14. Ginsberg HN, Zhang YL, Hernandez-Ono A. Metabolic syndrome: focus on dyslipidemia. Obesity. 2006 Feb (14)

15. Lim SM, Choi DP, Rhee Y, Kim HC. Association between obesity indices and insulin resistance among healthy Korean
adolescents: the JS high school study. PloS one. 2015 May dolescents: the JS high school study. PloS one. 2015 May 3;10(5):e0125238. [Full Text | DOI]

16. Lee HJ, Shin G, Park SH, Cho HK. Insulin resistance and visceral fat obesity in hyperlipidemia. Korean Circulation Journal. 1999 Jul 1,29(7):673-9. [Full Text | DOI]

17. Ericsson S, Eriksson M, Vitols S, Einarsson K, Berglund L, Angelin B. Influence of age on the metabolism of plasma low density lipoproteins in healthy males. The founal of clinical investigation. 1991 Feb 1;87(2):591-6. [PubMed_ | Full Text
| DOI]
18. Bekele S, Yohannes T, Mohammed AE. Dyslipidemia an associated factors among diabetic patients attending Durame General Hospital in Southern Nations, Nationalities, and Obesity: Targets and Therapy. 2017:10:265. Publed I Full Text | DOI] 